\title{
Compulsory Admission in Hong Kong: Balance between Paternalism and Patient Liberty
}

\author{
B Siu, EC Fistein, HW Leung, L Chan, CK Yan, A Lai, KK Yuen, KK Ng
}

\begin{abstract}
In Hong Kong, compulsory admission is governed by the Mental Health Ordinance Section 31 (detention of a patient under observation), Section 32 (extension of period of detention for such a patient), Section 36 (detention of certified patients), and the sections in Part IV for hospital order, transfer order, and removal order. Mental health professionals adopt both legal criteria and practice criteria for compulsory admission. The present study discusses the harm principle, the patient's decision-making capacity, the multi-axial framework for compulsory admission, and the balance between paternalism and patient liberty.
\end{abstract}

Key words: Hong Kong; Involuntary treatment, psychiatric; Mental health services; Patient admission

Dr Bonnie WM Siu, MBChB, MRCPsych, FHKCPsych, FHKAM (Psychiatry), FRCPsych, Department of Forensic Psychiatry, Castle Peak Hospital, Hong Kong SAR, China.

Dr EC Fistein, PhD, MRCPsych, School of Clinical Medicine, University of Cambridge, United Kingdom.

Mr HW Leung, BSc, MBA, Department of Forensic Psychiatry, Castle Peak Hospital, Hong Kong SAR, China.

Ms Lanly SY Chan, BSc, MBA, Department of Forensic Psychiatry and Old Age Psychiatry, Castle Peak Hospital, Hong Kong SAR, China.

Ms CK Yan, BSc, MSc (Management in Health Care), Department of Forensic Psychiatry, Castle Peak Hospital, Hong Kong SAR, China.

Ms Anita CH Lai, BSc, MSc (Nursing in Clinical Leadership), Department of Forensic Psychiatry, Castle Peak Hospital, Hong Kong SAR, China.

Mr KK Yuen, MSc, BN, Department of Forensic Psychiatry, Castle Peak Hospital, Hong Kong SAR, China.

Mr KK Ng, BSc, MSc (Nursing), Department of Forensic Psychiatry, Castle Peak Hospital, Hong Kong SAR, China.

Address for correspondence: Dr Bonnie WM Siu, Department of Forensic Psychiatry, Castle Peak Hospital, 15 Tsing Chung Koon Road, Tuen Mun, New Territories, Hong Kong.

Tel: 24567111; Fax: 24631644; Email:bonniew114m@yahoo.com

Submitted: 26 March 2018; Accepted: 23 July 2018

\section{Introduction}

In Hong Kong, the Mental Health Ordinance (MHO) governs the civil aspect of compulsory admission. ${ }^{1}$ Section 31 of the MHO authorises detention of a patient in a mental hospital for $<7$ days or in a place of safety (accident and emergency department) for $<48$ hours. The grounds for application are: (1) the patient is suffering from mental disorder, (2) of a nature or degree that warrants detention in a mental hospital for observation (with or without treatment), and (3) for the interests of the patient's health or safety or protection of others.

Application of detention requires completion of three forms. Form 1 may be made by a relative of the patient, a registered medical practitioner, or a public officer in the Social Welfare Department. A registered medical practitioner is a person registered in accordance with the Medical Registration Ordinance and needs not to be a psychiatrist. ${ }^{2}$ The applicant needs to have seen the patient personally within 14 days of application and states the reasons for detention. Form 2 contains written opinions of a registered medical practitioner who has examined the patient within 7 days. Form 3 is completed by a district judge or magistrate to authorise removal of a patient to a mental hospital for detention and observation. Before application, reasonable steps should be taken to inform the relatives of patients, and patients should be informed that they have the right to see the district judge or magistrate.

Section 32 is a one-off extension of detention of not more than 21 days upon expiry of Section 31. The opinion of two registered medical practitioners on the necessity of further detention for observation, investigation, and treatment is required in Form 4. The form will be countersigned by a district judge and forwarded to the medical superintendent of the mental hospital in which the patient is detained.

Section 36 authorises further detention of a patient in a mental hospital or in the Siu Lam Psychiatric Centre, upon expiry of a hospital order or a sentence of imprisonment. It requires two registered medical practitioners to examine the patient separately or together and conclude that: (1) the patient is suffering from mental disorder; (2) of a nature or degree that is appropriate to receive medical treatment in hospital; and (3) for the health or safety of the patient or for protection of others; and (4) such treatment cannot be provided unless the patient is detained. Additionally, patients who are neither suffering from mental illness nor psychopathic disorder may not be certified under Section 36 unless they are abnormally aggressive or their conduct is seriously irresponsible. To detain such patients, two registered medical practitioners should complete the Form 7 and forward it to a district judge to countersign who agrees that it would be dangerous to the voluntary patients 
or others if they are discharged from the mental hospital.

For the criminal aspect of compulsory admission, part IV of the MHO governs the admission of mentally disordered persons in criminal proceedings, transfer of mentally disordered persons under sentence, and remand of mentally incapacitated persons. Section 45 grants powers to the courts or magistrates to issue a hospital order to detain a patient in Siu Lam Psychiatric Centre or a mental hospital for a specified or unspecified period. Section 52 is for removal to a mental hospital of a person serving a sentence of imprisonment. Section 53 is for removal to a mental hospital of other prisoners (eg, remand prisoners). Persons who has been admitted to a mental hospital, pursuant to Sections 45, 52, 53, shall be treated as if they had been detained in a mental hospital in accordance with Section 36 , except that the power of the medical superintendent to permit absence on trial shall not be exercised; the persons shall not be discharged without the consent of the Chief Executive.

\section{Compulsory admission rate in Hong Kong}

The rate of compulsory admission is an indicator of underlying characteristics of mental health care laws. ${ }^{3}$ The decision-making process is influenced by multiple factors such as the practice of compulsory admission by different mental health care professionals. ${ }^{4,5}$ There are great variations in the compulsory admission rates as a percentage of all inpatient episodes across different European Union countries, from $3.2 \%$ in Portugal in 2000 to $30 \%$ in Sweden in $1997 .{ }^{3}$

In Hong Kong, between 2012/3 and 2016/7, there were 3657 compulsorily admissions and readmissions (57\% for males) to the Castle Peak Hospital, accounting for $26.9 \%$ of all admissions (Table 1). Most compulsory admissions occurred in age-groups 21-35, 36-50, and 51-65 years. Most compulsory admissions were authorised under Forms 1, 2, and 3 (Section 31), followed by Section 36. On
20 July 2017, the total number of inpatients was 751; of these, 337 (44.9\%) were admitted compulsorily. Psychiatric diagnoses were categorised according to the ICD 10th revision. ${ }^{6}$ The most common diagnosis was severe mental illness $(n=184)$, followed by mental retardation $(n=56)$ and pervasive developmental disorders (mainly autistic spectrum disorders) [n=16] (Table 2). On 17 July 2017, 69 patients (73.9\% males) aged 21 to 80 (mean, 49.8) years were compulsorily admitted under Section 36. The most common principal diagnosis was schizophrenia (68.1\%), followed by personality disorder $(10.1 \%)$ and mental retardation $(8.7 \%)$. The most common reasons for detention was insight problem $(65.2 \%)$, followed by psychotic symptoms $(55.1 \%)$ and risk of aggression (53.6\%) [Table 3].

\section{Compulsory admission (legal criteria)}

The rates of compulsory admission vary considerably in different jurisdictions and are influenced by the legal criteria and practice criteria of mental health professionals..$^{7-9}$ In some countries, compulsory admission is permitted as a preventative measure against self-harm or suicide. 3 In others, compulsory admission is restricted to those judged to pose a danger to themselves or others. In England and Wales, detention is also authorised when deemed necessary for the health or safety of the patient. Risk (of continued illhealth, deterioration, or physical harm) may not be the only criterion to consider. Dangerousness and grave disablement are grounds for compulsory admission, but there ought to be additional grounds such as treatability and lack of insight. ${ }^{10}$ In England and Wales, ongoing detention for treatment is authorised only if appropriate medical treatment is available for the condition, whereas in Scotland, medical treatment to stop deterioration of condition or to treat some symptoms must be available, and the patient must be significantly impaired to make decisions about treatment. ${ }^{8,9}$

Table 1. Compulsory admissions to Castle Peak Hospital from 2012/2013 to 2016/2017.

\begin{tabular}{|c|c|c|c|c|c|}
\hline \multirow[t]{2}{*}{ Parameter } & \multicolumn{5}{|c|}{ No. or No. $(\%)$ of patients } \\
\hline & $2012 / 2013$ & $2013 / 2014$ & $2014 / 2015$ & $2015 / 2016$ & 2016/2017 \\
\hline Admission & 2680 & 2695 & 2650 & 2792 & 2770 \\
\hline Voluntary & $2029(78.7)$ & $2018(74.9)$ & $1995(75.3)$ & $2011(72.0)$ & $1878(67.8)$ \\
\hline Compulsory & $651(24.3)$ & $677(25.1)$ & $655(24.7)$ & $781(28.0)$ & $892(32.2)$ \\
\hline \multicolumn{6}{|l|}{ Sex } \\
\hline Male & $394(60.5)$ & 397 (58.6) & $371(56.6)$ & $442(56.6)$ & $480(53.8)$ \\
\hline Female & $257(39.5)$ & $280(41.4)$ & $284(43.4)$ & $339(43.4)$ & 412 (46.2) \\
\hline \multicolumn{6}{|c|}{ Age group, y } \\
\hline$\leq 20$ & 5 & 9 & 8 & 11 & 28 \\
\hline $21-35$ & 119 & 146 & 136 & 189 & 235 \\
\hline $36-50$ & 208 & 185 & 177 & 222 & 226 \\
\hline $51-65$ & 197 & 194 & 186 & 200 & 200 \\
\hline $66-80$ & 76 & 78 & 99 & 97 & 137 \\
\hline$\geq 81$ & 46 & 65 & 49 & 59 & 66 \\
\hline
\end{tabular}


Table 2. Psychiatric diagnoses and application documents for compulsory admission of 337 patients on 20 July 2017.

\begin{tabular}{|c|c|c|c|c|c|c|}
\hline \multirow[t]{2}{*}{ Diagnosis } & \multicolumn{6}{|c|}{ No. of patients } \\
\hline & $\begin{array}{c}\text { Forms } \\
\text { 1, 2, or 3 } \\
\text { (Section 31) }\end{array}$ & $\begin{array}{c}\text { Certified } \\
\text { (Section 36) }\end{array}$ & $\begin{array}{c}\text { Hospital } \\
\text { Order } \\
\text { (Sections } \\
\text { 45/59E, 52B) }\end{array}$ & $\begin{array}{l}\text { Recall } \\
\text { (Section } \\
\text { 42B (3)) }\end{array}$ & Others & Overall \\
\hline Severe mental illness (F20-29) & 70 & 77 & 20 & 11 & 6 & 184 \\
\hline Affective disorders (F30-39) & 4 & 4 & 1 & 0 & 1 & 10 \\
\hline Stress-related disorders (F40-48) & 2 & 0 & 0 & 0 & 0 & 2 \\
\hline Dementia (F00-03) & 2 & 0 & 0 & 0 & 0 & 2 \\
\hline Pervasive developmental disorders (F84) & 12 & 4 & 0 & 0 & 0 & 16 \\
\hline Mental retardation (F70-F79) & 25 & 31 & 0 & 0 & 0 & 56 \\
\hline Other psychiatric diagnoses & 7 & 10 & 3 & 0 & 1 & 21 \\
\hline Pending & 41 & 4 & 0 & 1 & 0 & 46 \\
\hline Overall & 163 & 130 & 24 & 12 & 8 & 337 \\
\hline
\end{tabular}

Table 3. Reasons for compulsory admission of 69 patients under Section 36 on 17 July 2017.

\begin{tabular}{|lc|}
\hline Reasons for detention & No. $(\%)^{*}$ \\
\hline Insight problem & $90(65.2)$ \\
\hline Psychotic & $76(55.1)$ \\
\hline Risk of aggression / violence & $74(53.6)$ \\
\hline Social support problem & $34(24.6)$ \\
\hline History of aggression / violence & $30(21.7)$ \\
\hline Compliance problem & $26(18.8)$ \\
\hline Aggressive / violent & $15(10.9)$ \\
\hline Self-neglect & $12(8.7)$ \\
\hline Mood disorder & $4(2.9)$ \\
\hline Risk of Suicide / self-harm & $3(2.2)$ \\
\hline History of suicide / self-harm & $2(1.4)$ \\
\hline Suicidal / self-harm & $0(0.0)$ \\
\hline Others & $24(17.4)$ \\
Rehabilitation & $7(28.0)$ \\
Substance abuse & $6(24.0)$ \\
History of indecency & $3(12.0)$ \\
Need to live in a supervised & $2(8.0)$ \\
accommodation & $1(4.0)$ \\
Compulsive water drinking leading to & $1(4.0)$ \\
severe electrolyte disturbance & $1(4.0)$ \\
Erroneous judgement & $1(4.0)$ \\
High risk of absconding & $1(4.0)$ \\
High risk of sex-related offence & $1(4.0)$ \\
Mentally unfit to make consent for & $1(4.0)$ \\
psychiatric treatment & $1(4.0)$ \\
Nuisance to public & Talk non-sense
\end{tabular}

Patients could have more than one reason for detention and had two prescribed forms reviewed
Independent review and use of the least restriction necessary are essential. The World Health Organization Mental Health Policy and Service Guidance Package Mental Health Legislation and Human Rights suggests a high dangerousness-based risk threshold for people capable of making decisions about treatment, with a lowerrisk threshold, based on the need for treatment to improve health or function, for people with impaired decisionmaking capacity. ${ }^{11}$ The Recommendations of the Council of Europe recommends a relatively high-risk threshold to limit compulsory admission to patients at risk of harming others or experiencing significant or serious deterioration. ${ }^{12}$ The United Nation Convention on the Rights of Persons with Disabilities states that no one should be deprived of their legal capacity on the grounds of disability. When making treatment decisions on behalf of those who cannot, as a result of functional impairment, priority should be given to the current will and preferences of the person on whose behalf the decision is being made. ${ }^{13}$

\section{Multi-axial framework for compulsory admission}

Fistein et $\mathrm{al}^{9}$ developed a multi-axial framework that involves diagnostic threshold, treatability threshold, risk threshold, incapacity threshold, and review process for comparative analysis of the legislation governing compulsory admission of Commonwealth countries (Table $4)$.

The MHO of Hong Kong is analysed based on this multi-axial framework. For diagnostic threshold, mental disorder is defined as a state of arrested or incomplete development of mind, psychopathic disorder, or any other disorder or disability of mind that does not amount to mental handicap. The inclusion of the broad term "any other 
Table 4. Multi-axial framework ${ }^{9}$ for comparative analysis of the legislation governing compulsory admission of Commonwealth countries.

\begin{tabular}{|c|c|}
\hline \multicolumn{2}{|c|}{ Axis 1: diagnostic threshold } \\
\hline Level 1 & No definition of mental disorder in the legislation, and no standard set for determining its presence \\
\hline Level 2 & Mental disorder determined by legal professionals and emphasise a perceived need for control or containment \\
\hline Level 3 & Presence of phenomena that impair mental functioning \\
\hline Level 4 & Diagnosis of particular syndromes or classes of syndrome \\
\hline Level 5 & $\begin{array}{l}\text { Diagnosis based on an internationally recognised system of classification, eg, 10th Revision of International } \\
\text { Classification of Diseases or 4th Edition of Diagnostic and Statistical Manual }\end{array}$ \\
\hline \multicolumn{2}{|c|}{ Supplement to axis 1: exclusion criteria } \\
\hline Group a & Ethnicity; religious, political, cultural or philosophical beliefs or practices \\
\hline Group b & Criminal, irresponsible or antisocial behaviour \\
\hline Group c & Sexual preference, identity or practices \\
\hline Group d & Misuse of alcohol or drugs \\
\hline Group e & Intellectual disability \\
\hline Group $\mathrm{f}$ & Personality disorder (may be limited to cluster B or to anti-social personality disorder) \\
\hline \multicolumn{2}{|c|}{ Axis 2: treatability threshold } \\
\hline Level 1 & No therapeutic intent required \\
\hline Level 2 & Requirement for therapeutic intent for involuntary admission \\
\hline Level 3 & Requirement that treatment for the condition is available \\
\hline Level 4 & Treatment must be likely to alleviate the condition or prevent deterioration \\
\hline \multicolumn{2}{|c|}{ Axis 3: risk threshold } \\
\hline Level 1 & Detention permitted when degree of risk is unknown \\
\hline Level 2 & Detention needed to improve health or ability to function \\
\hline Level 3 & Detention needed to prevent deterioration \\
\hline Level 4 & Detention needed to prevent a significant or serious deterioration or psychological harm to the patient or others \\
\hline Level 5 & Detention needed to prevent immediate or imminent physical harm to the patient or others \\
\hline \multicolumn{2}{|c|}{ Axis 4: incapacity threshold } \\
\hline Level 1 & Treatment permitted without a capacity assessment or when the patient is able to make a treatment decision \\
\hline Level 2 & $\begin{array}{l}\text { Incapacity is indicated when the patient makes an irrational choice, or when the outcome of the patient's } \\
\text { treatment decision is deemed unreasonable }\end{array}$ \\
\hline Level 3 & Incapacity is indicated when the patient lacks the functional abilities required to make the treatment decision \\
\hline \multicolumn{2}{|c|}{ Axis 5: review process } \\
\hline Level 1 & No review or appeal process \\
\hline Level 2 & Right of appeal but no automatic independent legal review \\
\hline Level 3 & Regular automatic independent legal review \\
\hline Level 4 & Monthly automatic independent legal review \\
\hline
\end{tabular}


disorder or disability of mind" puts the MHO at level 1 of this axis. There are exclusions by reason of promiscuity or other immoral conduct, sexual deviancy or dependence on alcohol or drugs (groups c and d), and intellectual disability (group e) unless associated with abnormally aggressive or seriously irresponsible conduct. For treatability threshold, Section 36(1) stipulates that "the patient must be suffering from a mental disorder of a nature or degree appropriate to receive medical treatment in hospital," but does not include a test of treatability, putting the MHO on level 1 of this axis. For risk threshold, Section 36(1) stipulates that detention must be "necessary for the health or safety of the patient or for the protection of other persons", putting the MHO on level 2 of this axis. For incapacity threshold, the $\mathrm{MHO}$ does not require a test or assessment for compulsory admission, which puts it on level 1 of this axis. Therefore, the $\mathrm{MHO}$ has a low risk threshold that is not moderated by a test of decision-making capacity, which is inconsistent with the international guidance. For review process, the Mental Health Review Tribunal (Section 59A) automatically reviews the detention of certified patients every 2 years (if the patient or relative does not apply for review annually). This puts the MHO on level 3 of this axis.

\section{Compulsory admission (practical criteria)}

Practical criteria are salient in the determination of compulsory admission. For example, clinicians may compensate for the absence of a legal requirement for compulsory admission in patients with impaired decisionmaking capacity. 'Lack of insight' is one of the reasons for compulsory admission (albeit insight and decisionmaking capacity are not identical). Similarly, although the legal requirement for quasi-judicial review of detention may be infrequent, in between the automatic reviews, the clinical condition and the discharge plan of the patients are reviewed regularly by multidisciplinary clinical team with involvement of relatives.

The decision to detain involves a constellation of factors. ${ }^{4,14-16}$ In a study in Canada, significant factors were legal commutability (ie, dangerousness to self and/ or others, inability to care for self), clinical treatability, alternative resources, and psychotic symptoms. ${ }^{14}$ In England and Wales, decisions to detain are based on five key themes: (1) diagnosis, (2) availability of alternatives to detention, (3) likelihood of response to treatment, (4) risk assessment, and (5) the patient's capacity to make decisions about treatment. ${ }^{16}$ In addition, clinicians may use practical (operational) criteria to identify patients in whom the principle of soft paternalism may be applied. ${ }^{16}$

\section{Balancing duty of care and liberty}

Clinicians should balance between the patient's liberty and self-determination and the duty of care and treatment of patients and protection of the society. ${ }^{9}$ Informed consent is important. The justifications to limit liberty include prevention of harm to the person himself (paternalism) or others. ${ }^{9}$ Nonetheless, paternalism is only justifiable if the decision-making capacity is significantly impaired., ${ }^{9,17}$ Interference to prevent harm to others is justified because interference with an assailant's autonomy preserves both the autonomy and the physical integrity of any potential victims. ${ }^{9,18,19}$ Rights to be treated and protected are as important as the rights to liberty. ${ }^{20}$ An authorisation to detain can be a duty to detain when there is a high and immediate risk of persons taking their own lives, a failure to do so can be considered medical negligence and may also be a breach of human rights. ${ }^{21}$ In a court case in the United Kingdom, a voluntary psychiatric patient hanged herself after being allowed to spend the weekend with her family. ${ }^{22}$ The Supreme Court unanimously held that the failure of the hospital staff to detain the patient was a breach of her right to life under Article 2 of the European Convention on Human Rights. ${ }^{23}$ Given her history of depression and self-harm and a previous suicide attempt, the hospital staff should have used their powers to detain the patient under the Mental Health Act to protect her from the 'real and immediate risk of suicide'. ${ }^{24}$ In Hong Kong, there is no such law yet on medical negligence in relation to failure to detain a patient with high risk of suicide.

In European countries, decision to detain may be made with reference to the European Convention on Human Rights and Article 5 on right to liberty. ${ }^{25}$ One example is a 47-year-old man with autism and learning disabilities who was an inpatient of the Bournewood Hospital for 3 months in $1997 .{ }^{26}$ The patient was not detained under the Mental Health Act, but was accommodated in his own best interests under the common law doctrine of necessity. ${ }^{24,26}$ The patient brought legal proceedings (unlawfully detained) against the managers of the Bournewood Hospital. ${ }^{26}$ The case was referred to the European Court of Human Rights, and Article 5 was mentioned. ${ }^{26}$ In Hong Kong, two sources of constitutional rights can serve to protect compulsorily detained patients. ${ }^{27}$ Article 28 of the Basic Law stated that no resident shall be subjected to arbitrary or unlawful arrest, detention, or imprisonment. ${ }^{28}$ Article 5 of the Hong Kong Bill of Rights Ordinance stated that everyone has the right to liberty and security and no one shall be subjected to arbitrary arrest or detention. ${ }^{29}$ The most important spirit of the amendments to the Mental Health Regulations under Part V (general provisions) of the MHO is to re-emphasise the patient's human rights as an inpatient of a mental hospital, such as rights to receive visitors, make or receive telephone calls, send or receive a postal article, refused enforced working, and possess or receive certain articles. ${ }^{30}$ Previously, the medical superintendent had the power to forbid a patient sending a letter to a Legislative Councillor. ${ }^{30}$

\section{Procedural safeguards}

In two patients, a district judge refused to countersign the application for Section 36 on the grounds that the previous detention for observation (Section 31) or extended 
observation (Section 32) had already been expired. The district judge viewed the reasons for detention under Section 36 to be irrelevant and the Section 36 could not be used after the expiry of the detention for observation or extended observation..$^{31,32}$ The Hospital Authority challenged the district judge's decision of not countersigning through judicial review. ${ }^{33}$ It was held that district judges are not permitted to question medical opinions unless a person has been treated unlawfully, because medical matters should be left to doctors and not judges. However, district judges may be in a difficult position if they are not allowed to question the medical opinion. ${ }^{27} \mathrm{Cheung}^{34}$ suggested that the requirement for the signature of a magistrate or judge may be removed for Sections 31, 32, and 36, because involvement of a judge creates administrative difficulties and potentially delays treatment. Abuse of application can then be prevented by a more stringent statutory review after detention (eg, a shorter statutory review period). In the United Kingdom, the period for the first detention would be up to 6 months for patients detained under Section 3 of the Mental Health Act. ${ }^{24}$ Subsequent detention for further 6 months needs to be reviewed by mental health professionals. ${ }^{24}$

Cheung $^{34}$ suggested replacing 'registered medical practitioner' with 'approved clinician', and 'approved social worker' with 'approved mental health professional' in the MHO of Hong Kong, because it is operationally appropriate to allow other disciplines such as community psychiatric nurses, occupational therapists, and clinical psychologists to be applicants for Form 1 (Section 31). In our opinion, medical professionals should be involved in the decision for compulsory admission, regardless who initiates the application. In fact, for most patients, the decision for compulsory admission is made by a multidisciplinary team with involvement of patients and their relatives.

\section{Attitudes of patients, relatives, and public}

Several studies have reported positive attitudes toward compulsory admission by patient, patient's relatives, and the public..$^{35-37}$ In one study, $75 \%$ of patients considered compulsory admission appropriate and $80 \%$ considered hospital stay helpful, but only one of the 31 relatives considered compulsory admission appropriate.$^{35}$ In another study, $>70 \%$ of the general population, people with mental disorders who had received treatment, and their relatives were in favour of compulsory hospital admission..$^{36}$ More than $70 \%$ of the public displayed a positive attitude toward compulsory admission. ${ }^{37}$ In addition, patients' perceived coercion $^{38-40}$ and consequences ${ }^{41}$ of compulsory admission has been reported. Patients and their relatives should be provided with written information on the potential impact of detention (eg, refusal of tourist visa) along with a list of organisations that can provide advice. ${ }^{41}$

\section{Acknowledgements}

We thank Dr M Lam and Dr E Cheung for their support in presentation in a talk 'Compulsory Mental Health Treatment in Hong Kong: Which Way Forward?' in August 2017. This paper is a summary of the talk.

\section{Declaration}

The authors have no conflict of interests to declare.

\section{References}

1. Mental Health Ordinance. Cap. 136. Laws of Hong Kong.

2. Medical Registration Ordinance. Cap. 161. Laws of Hong Kong.

3. Salize HJ, Dressing H. Epidemiology of involuntary placement of mentally ill people across the European Union. Br J Psychiatry 2004;184:163-8. Crossref

4. Engleman NB, Jobes DA, Berman AL, Langbein LI. Clinicians' decision making about involuntary commitment. Psychiatr Serv 1998;49:941-5. Crossref

5. Sattar SP, Pinals DA, Din AU, Appelbaum PS. To commit or not to commit: the psychiatry resident as a variable in involuntary commitment decisions. Acad Psychiatry 2006;30:191-5. Crossref

6. International Statistical Classification of Diseases and Related Health Problems. Geneva, World Health Organization; 1992.

7. Appelbaum PS. Almost a revolution: an international perspective on the law of involuntary commitment. J Am Acad Psychiatry Law 1997;25:135-47.

8. Gostin LO. 'Old' and 'new' institutions for persons with mental illness: treatment, punishment or preventive confinement? Public Health 2008; 122:906-13. Crossref

9. Fistein EC, Holland AJ, Clare IC, Gunn MJ. A comparison of mental health legislation from diverse Commonwealth jurisdictions. Int J Law Psychiatry 2009;32:147-55. Crossref

10. Listening to experience: an independent inquiry into acute and crisis mental healthcare. Available from: http://www.mind.org.uk/ media/211306/listening_to_experience_web.pdf. Accessed 1 Jan 2017.

11. World Health Organization mental health policy and service guidance package: mental health legislation and human rights. Geneva: World Health Organization; 2003.

12. Concerning the Protection of the Human Rights and Dignity of Persons with Mental Disorder: Council of Europe Committee of Ministers. 2004.

13. United Nation Convention on the Rights of Persons with Disabilities. Available from: http://www.un.org/disabilities/documents/convention/ convoptprot-e.pdf. Accessed 1 Jan 2017.

14. Bagby RM, Thompson JS, Dickens SE, Nohara M. Decision making in psychiatric civil commitment: an experimental analysis. Am J Psychiatry 1991;148:28-33. Crossref

15. Hoge SK, Lidz CW, Eisenberg M, Gardner W, Monahan J, Mulvey E, et al. Perceptions of coercion in the admission of voluntary and involuntary psychiatric patients. Int J Law Psychiatry 1997;20:16781. Crossref

16. Fistein EC, Clare IC, Redley M, Holland AJ. Tensions between policy and practice: a qualitative analysis of decisions regarding compulsory admission to psychiatric hospital. Int J Law Psychiatry 2016;46:507. Crossref

17. McMillan JR. Mental illness and compulsory treatment. In: Ashcroft RE, Dawson A, Draper H, McMillan JR, editors. Principles of Health Care Ethics. 2nd ed. John Wiley and Sons; 2007.

18. Feinberg J. Harm to Others. New York: Oxford University Press; 1984.

19. Mill J. On liberty. John Stuart Mill on Liberty and Other Essay. Oxford: Oxford University Press; 1998.

20. Chodoff P. Involuntary hospitalization of the mentally ill as a moral issue. Am J Psychiatry 1984;141:384-9. Crossref

21. Wang DWL, Colucci E. Should compulsory admission to hospital be part of suicide prevention strategies? BJPsych Bull 2017;41:16971. Crossref 
22. Rabone \& Anor v Pennine Care NHS Foundation Trust. 2012. United Kingdom Supreme Court 2.

23. European Convention of Human Right Article 2. Available from: www.echr.coe.int/Documents/Convention_ENG.pdf. Accessed 1 Jan 2017.

24. Department of Health. Mental Health Act. London: Her Majesty's Stationery Office; 2007.

25. European Convention of Human Right Article 5. Available from: www.echr.coe.int/Documents/Convention_ENG.pdf. Accessed 1 Jan 2017.

26. The "Bournewood" Case. Available from: http://www.communitycare. co.uk/2005/02/07/the-bournewood-case/. Accessed 1 Jan 2017.

27. Cheung D. The compulsory psychiatric regime in Hong Kong: Constitutional and ethical perspectives. Int $\mathrm{J}$ Law Psychiatry 2017;50:24-30. Crossref

28. Basic Law of Hong Kong. Available from: www.basiclaw.gov.hk. Accessed 1 Jan 2017.

29. Hong Kong Bill of Rights Ordinance. Cap 383. Laws of Hong Kong.

30. Cheung HK. The new mental health ordinance 1996 to 1997 - a reference guide for physicians and mental health workers. Hong Kong J Psychiatry 2000;10:3-13.

31. Re Patient L [2001] I HKLRD (Yrbk) 584.

32. Re Patient O [2001] HKEC 509.
33. Hospital Authority v a District Judge [2002] 2 HKC 98.

34. Cheung HK. What we should consider when we next amend the Mental Health Ordinance of Hong Kong. Hong Kong J Psychiatry 2009;19:53-6.

35. Srinivasan DP, Soundararajan PC, Hullin RP. Attitudes of patients and relatives to compulsory admission. Br J Psychiatry 1980;136:200-1. Crossref

36. Lauber C, Falcato L, Rössler W. Attitudes to compulsory admission in psychiatry. Lancet 2000;355:2080. Crossref

37. Lauber C, Nordt C, Falcato L, Rössler W. Public attitude to compulsory admission of mentally ill people. Acta Psychiatr Scand 2002;105:3859. Crossref

38. Monahan J, Hoge SK, Lidz C, Roth LH, Bennett N, Gardner W, et al. Coercion and commitment: understanding involuntary mental hospital admission. Int J Law Psychiatry 1995;18:249-63. Crossref

39. Nicholson RA, Ekenstam C, Norwood S. Coercion and the outcome of psychiatric hospitalization. Int J Law Psychiatry 1996;19:20117. Crossref

40. Hiday VA, Swartz MS, Swanson J, Wagner HR. Patient perceptions of coercion in mental hospital admission. Int $\mathrm{J}$ Law Psychiatry 1997;20:227-41. Crossref

41. Ashmore R. Visa refusal following compulsory hospital admission under the Mental Health Act 1983 (England and Wales): fact or fiction. J Psychiatr Mental health Nurs 2015;22:390-6. Crossref 